\title{
DOS NOTAS (I. GLOSAS SOBRE LO DIACRÓNICO EN LINGÜÍSTICA Y EN LITERATURA. II. EN LOS ORÍGENES DE LA NOVELA DECIMONÓNICA)
}

FRANCISCO ABAD

UNED. Madrid

\section{RESUMEN}

En la primera de estas Notas se glosan algunos pasajes de los cuatro capítulos primeros de la obra clásica de Eugenio Coseriu Sincronía, diacronía e historia, haciendo extensivas las glosas también a lo diacrónico tal como existe en la literatura. En la segunda Nota se ilustra el nacimiento de la novela moderna española que ocurre hacia fines del siglo XVIII y en las décadas iniciales del XIX; en tanto ejemplo analítico se comenta el contenido anticlerical y en contra de las instancias absolutas de la novela Cornelia Bororquia de Luis Gutiérrez, y se apuntan los planteamientos ilustrados de su autor.

A Dario Villanueva, amigo querido que gusta de las referencias que le hago a los textos de Coseriu.

Palabras iniciales

Entre los textos clásicos en el estudio de las cuestiones diacrónicas teóricas se encuentra la obra de Eugenio Coseriu Sincronía, diacronía e historia; 
nuestra experiencia nos dice que los estudiantes no siempre la encuentran fácil, e incluso algún conocido catedrático de Historia de la lengua nos ha dicho personalmente que en efecto encuentra difíciles algunos de sus pasajes. El modesto propósito que tenemos ahora es el de empezar a glosar algunas páginas y párrafos de los cuatro capítulos iniciales tal texto, glosa que ojalá resulte útil a nuestros alumnos y les estimule a nuevas lecturas; en tanto nos sea posible haremos referencia paralelamente a los problemas de la diacronía literaria, que creemos quedará así iluminada en algo.

\section{SOBRE LA DIACRONÍA}

Estamos ante un texto publicado por vez primera en 1957 en el que su autor se refiere al ámbito de la linguística italiana al que - nos dice- - «yo mismo pertenezco» (Coseriu, 1978: 52), en alusión a sus años iniciales, años formativos que explican su pensamiento no positivista ni naturalista; luego sin duda Coseriu se ha incorporado a los ámbitos de la ciencia linguística de Alemania y de los países de habla española.

Advierte nuestro autor que «la antinomia sincronia-diacronía no pertenece al plano del objeto sino al plano de la investigación: no se refiere al lenguaje, sino a la lingüística» (Ibid.: 14). El hecho es complejo y cabe mantener en cambio que ciertamente en el idioma en tanto objeto coexisten en un sentido lo sincrónico con lo diacrónico, pues los rasgos sistemáticos sucesivos no se sustituyen de manera lineal y con solución de continuidad sino que se entremezclan en un único momento dado; no obstante todos los estratos diacrónicos coexistentes en ese momento dado funcionan en una misma sincronía, sus elementos respectivos se oponen unos a otros y contrastan unos con otros en esa sola sincronía, y la mayoría de los hablantes no saben que se adscriben a diferentes diacronías: por tanto la antinomia entre lo sincrónico y lo diacrónico se refiere desde luego a la lingüística pero asimismo al lenguaje, en el sentido de que en un momento particular ya decimos que todos los elementos procedentes de diacronías distintas se integran en una misma sincronía de funcionamiento, y tal sincronía es la única que perciben casi todos los hablantes.

Existe - diríamos - una continuidad entre el lenguaje y la lingüística: hay hechos que no son sólo una distinción efectuada por la ciencia idiomática sino que asimismo consisten en una realidad del lenguaje; en este caso es real la integración en una sola sincronía funcional de los diferentes estratos diacrónicos parciales en que consiste todo idioma. El propio Coseriu se da cuenta de esto pocas páginas más adelante, cuando mantiene que por ejemplo los arcaísmos «en cuanto existen y funcionan, son elementos actuales» (Ibid.: 18). 
En la realidad de la serie literaria creemos que existe por contra una mayor continuidad entre lo diacrónico y lo sincrónico. El pasado artístico-verbal opera siempre sobre el autor cuando se pone a escribir, y a la vez la obra que hace entra en el sistema sincrónico a que dan lugar todas las obras surgidas en un momento temporal dado: tanto la diacronía como la sincronía literarias se hallan así muy unidas en la realidad, mientras en lo lingüístico el hablante en cuanto hablante la mayor parte de las veces no posee ningún sentimiento diacrónico.

La literatura se constituye en el seno mismo de la historia o serie literaria, por convergencia o en discrepancia con ella; a la vez las obras de arte verbal se afirman en su convergencia o contraste sincrónico con las demás que coexisten con ella. El Lazarillo — valga este ejemplo- se afirmó por su originalidad en el modo de la narración frente a la serie o tradición literaria, y a la vez se afirmó por contraste con la novela pastoril o morisca de hacia los mismos años.

En literatura la antinomia sincronía-diacronía sí pertenece al plano del objeto, y asimismo al de la investigación. Se da una continuidad, una falta de solución de continuidad, entre lo diacrónico y lo sincrónico en el arte verbal; en el lenguaje ocurre menos, y ya queda dicho que para la conciencia común de los hablantes no hay sino sincronía.

Alguna vez se ha mantenido que «los distintos representantes de la estilística [...] ilustran toda una galería de negaciones sistemáticas o de omisiones muy significativas del principio diacrónico» (García Berrio, 1973: 287); nosotros no creemos sinceramente que las cosas sean así. Si reparamos en los análisis estilísticos del propio Menéndez Pidal —casi siempre olvidados-o en los de Dámaso Alonso y Rafael Lapesa, comprobaremos que ellos siempre operan con el principio de la historia o serie diacrónica en el análisis de la lengua literaria. Don Ramón estampó incluso un párrafo en el que de manera intuitiva pero muy explícita exponía el por qué del sucederse de los diferentes sistemas de estilo en la diacronía literaria; decía Menéndez Pidal:

La evolución lingüística [y estilística ...] va condicionada por un factor psicológico constante, y es la necesidad de reparar un instrumento que se usa todos los instantes del día y que se embota con el uso, la necesidad de aguzar a menudo el filo de la palabra, renovándola para el acto de grabar sobre la distracción y el cansancio del oyente. $Y$ tal renovar suele moverse entre dos extremos: ora espontaneidad, sencillez, llaneza; ora artificio, complicación, reconditez. Gran parte de la historia de la lengua literaria se explica por ese vaivén: a una época en que la expresión artística aspira a iluminar el espíritu con blanca claridad sucede otra que opera sobre el relajamiento de la atención, esforzando las coloraciones o buscando penumbras y hasta 
oscuridad; acciones y reacciones, movimiento pendular, aunque no ciertamente simple sino turbado por impulsos varios (1942: 53, subrayado por nosotros).

Vemos que no resulta ajena a la estilística de Menéndez Pidal la consideración de la diacronía, antes bien funda en ella la razón del sucederse de la expresión artística, a veces clara y a veces oscura. No en todo sin embargo cabe asentir a don Ramón, quien parece equiparar la sencillez con la claridad: la elocución literaria puede ser clara pero no sencilla sino compleja; todo texto artístico posee un artificio interno y ninguno resulta de construcción sencilla. Claridad no es espontaneidad.

En todo caso creemos nosotros que se comprueba cómo la estilística de Menéndez Pidal no niega ni omite la esencial dimensión diacrónica que tiene lo literario.

Una monografía - por otra parte - como la que dedicó Dámaso Alonso a la lengua poética de Góngora se encuentra fundamentada asimismo en el sucederse de la serie artística: Góngora es entendido por su estudioso en cuanto fija e intensifica varios procedimientos estilísticos normales ya en la lengua poética renacentista; don Dámaso operó pues principalmente con el principio de lo diacrónico, en su indagación acerca del estilo característico de don Luis.

Lapesa por su lado escribió pronto —en 1947- unas líneas (repetidas luego por él en otro trabajo suyo) que analizaban el estilo elocutivo de Garcilaso justamente en cuanto se insertaba en la serie poética castellana y se oponía a lo que encontraba en la misma. Nuestro autor habla ya de «la revolución literaria llevada a cabo por [...] Garcilaso» (Lapesa, 1947: 5), es decir, de una poética opuesta a la que le venía del Cuatrocientos, y explica respecto de Boscán y Garcilaso:

Los metros que introducían eran lentos, reposados, menos pendientes que el octosíabo de la rima acuciadora [...]. El moroso discurrir de endecasilabos y heptasílabos [...] era el ritmo adecuado para la exploración del propio yo en detenidos análisis y para expresar el arrobo contemplativo ante la naturaleza. Estos eran los dos grandes temas de la nueva escuela. Petrarca, «el primer hombre moderno», había dado la pauta para el escrutinio del interior anímico: sentimientos, contradicciones, estados de alma, en suma. Y los poetas, al explorar así el propio espíritu, cobraban conciencia de sí mismos y contribuían al descubrimiento del individuo, hecho capital del Renacimiento (Ibid.: 6).

Al margen de las novedades del contenido, estamos en efecto ante metros lentos, no ante un metro corto que hace constantemente presente el artificio de 
la rima: son dos poéticas, que Lapesa veía oponerse en la sucesión diacrónica de la serie literaria. Se trataba por tanto de una revolución literaria que venía a cambiar un estado de cosas.

El análisis estilístico de Rafael Lapesa, y antes los de Menéndez Pidal y Dámaso Alonso, no sólo no se desentendían de la historia poética, sino que resultaban posibles merced a la apelación al sucederse de la serie artística; en literatura no existe discontinuidad entre lo sincrónico y lo diacrónico, y así no cabe que exista tampoco tal discontinuidad en su estudio: desde luego no existía en la escuela estilística, que creemos nosotros modestamente - a la vista de los hechos-que no omitió ni negó el principio de lo diacrónico.

\section{LA LENGUA EN TANTO ARCHISISTEMA}

El problema de la concurrencia sincrónica de diferentes técnicas del hablar lleva al concepto de lengua histórica o idioma, y sobre el mismo escribe Coseriu:

La lengua funcional no debe confundirse con la lengua histórica o idioma (como por ej. la lengua española, la lengua francesa, etc.). Una lengua histórica puede abarcar no sólo varias normas sino también varios sistemas. [...] El «español» es por lo tanto un «archisistema» dentro del cual quedan comprendidos varios sistemas funcionales (1978: 56).

Ciertamente es una idea capital la de que las lenguas son archisistemas, esto es, amalgamas de técnicas distintas de hablar y en ningún caso códigos homogéneos distribuidos uniformemente en la comunidad idiomática. La lengua consiste desde luego en un sistema o código, porque si no fuera así no resultaría posible la intercomprensión, pero tal código no consta siempre de unos únicos procedimienros sino que procedimientos distintos coexisten para lograr el mismo fin de la comunicación inteligible.

La lengua histórica de que se trate posee en un momento dado varias normas coexistentes o concurrentes, varios usos alternativos que tienen vigencia, y no sólo distintos hechos de norma lingüística sino distintos hechos de sistema: toda lengua es en verdad y ciertamente un archisistema, pero archisistema actualizado en una única sincronía global. La actualización sincrónica de todos sus elementos componentes hace que la distinción entre sincronía y diacronía no sea sólo un recurso analítico de los estudiosos sino una realidad efectiva del lenguaje. 
Coseriu ilustra bien cómo las tenidas por leyes o excepciones diacrónicas pueden no ser sino resultados respectivos de las varias técnicas mezcladas del hablar en que consiste históricamente una lengua:

Las palabras que no obedecen a tal o cual «ley fonética» proceden de hablares en los que los cambios correspondientes no ocurrían. En otros términos esas «excepciones» aparecen como tales sólo si se pretende considerar la lengua como una sola tradición homogénea, pero se vuelven formas «regulares» si se tiene en cuenta que una lengua histórica es resultado de la interacción entre varias tradiciones lingüísticas (Ibid.: 103).

En las técnicas del hablar pueden darse la tendencia al vulgarismo y la tendencia al cultismo, y tales tendencias respectivas poseen una distribución geográfica o social distinta: esa procedencia de un subgrupo de la comunidad hablante lleva a que los resultados coexistentes resulten distintos, y ocurre por la mezcla histórica de tradiciones en que consiste el idioma.

Recordando a Saussure subraya Coseriu cómo ««nada aparece en el sistema que no haya existido antes en la norma" y viceversa, nada desaparece del sistema funcional sino a través de una larga selección realizada por la norma» (Ibid., p. 129). En verdad los rasgos lingüísticos que los hablantes llegan a codificar en tanto rasgos propios del sistema han surgido antes en normas parcialmente distribuidas en la comunidad: son rasgos que han tenido origen y se han hecho frecuentes en subgrupos de hablantes, y que por difusión en el conjunto se han incorporado en tanto rasgos generalizados y que pertenecen ya al código idiomático, es decir, a la lengua toda.

Agudamente señala nuestro autor el otro lado del asunto, que nada desaparece del sistema funcional si antes esa desaparición no se ha hallado presente en la norma lingüística, o por mejor decir, en una de las normas lingüísticas coexistentes en la comunidad global que emplea una lengua; una distinción fonemática, una determinada construcción gramatical, etc., pueden desaparecer si antes han desaparecido en el hablar normal (esto es, estadísticamente consolidado) de un subgrupo del conjunto de los hablantes, y tal extinción llega a extenderse y consolidarse también en todos los hablantes.

De la serie literaria asimismo cabe decir -al igual que de las lenguas naturales - que constituye un archisistema, y lo mismo diacrónica que sincrónicamente. La riqueza de una tradición literaria reside en verdad en esa riqueza de géneros, subgéneros y estilos que dan lugar a lo que podemos llamar el archisistema en que consiste una literatura; la literatura castellana -e. gr.- es el archisistema de sus (sub)géneros y estilos, que se suceden oponiéndose unos 
a otros y que sincrónicamente asimismo contrastan unos con otros; en un momento dado contrastan así la novela realista burguesa y la novela lírica casi poemática, y por ejemplo un subsistema literario decae y es abandonado en cuanto forma de escribir, y hay que crear otro u otro que lo sustituyan: en conjunto lo que se da es el archisistema que constituye una literatura dada.

\section{LAS LENGUAS Y SUS NOMBRES}

Seguimos glosando a Coseriu y encontramos en su libro estas palabras:

Una lengua [...] es por su naturaleza un «objeto histórico». Un objeto histórico "por su naturaleza» es un objeto individuado absolutamente dentro de su especie como tal y no otro [....] es decir, un objeto que tiene nombre propio (Ibid., p. 20).

El nombre propio posee la característica gramatical de individualizar, es decir, de señalar a un ser entre los otros de su clase, y así el nombre de un idioma lo individualiza en tanto único y distinto de los demás; cada idioma resulta individuado porque es justamente un objeto histórico y la historia lo ha hecho distinto.

Como dice nuestro autor una lengua es un objeto histórico, y su consistencia se identifica con su historia: el perfil de una lengua es el que ha adquirido a lo largo de la diacronía. Se trata de un objeto individuado dentro de su clase, y para señalarlo entre los demás le damos un nombre propio.

En el caso de nuestra lengua patrimonial sabido es que existe una monografía acerca de su nombre individualizador: la que hizo Amado Alonso (1938), si bien no parece haberse observado algo que importa: esta monografía resulta un tanto incompleta desde el siglo XVIIl y salta sobre el Ochocientos probablemente por falta de la documentación necesaria. Amado escribía en Buenos Aires, la guerra española no le permitía contactos regulares con sus maestros y amigos, el «Centro de Estudios Históricos» ya había dejado de existir, y así se echa de ver que en efecto textos importantes parece no haberlos tenido a su alcance. Desde luego la menor atención a todo lo que ocurre tras 1713 es usual en la escuela de Menéndez Pidal, pero en el caso concreto de este libro de Amado creemos que pesa la falta de acceso a obras de relieve que las circunstancias le impusieron.

En cuanto a lo literario desde luego cualquiera de las literaturas es un «objeto histórico», y su consistencia concreta se deriva de su historia. Tiene además -al igual que las lenguas- un nombre propio. 
Las lenguas y las literaturas específicas se hacen como tales en su devenir: una literatura consta de géneros o subgéneros que van apareciendo a lo largo de su historia, de modos de estilo diferenciados, etc., y según esos géneros y maneras de estilo se individualiza y caracteriza. Hace ya años nos referimos al problema de la caracterización de una literatura, y entonces postulamos que no cabía hablar por ej. del «realismo» de la literatura española, sino de las diferentes clases de realismo con que estaban hechos los sucesivos textos: uno es acaso el realismo de la literatura costumbrista decimonónica y otro el realismo galdosiano. Caracterizar una literatura ha de consistir — manteníamos - «en describir y explicar cómo ha sucedido su despliegue o desarrollo, esto es, en dar cuenta del sucederse de la serie. Caracterizan y definen a la Literatura española sus cambiantes poéticas» (Abad, 1983: 27-65).

En nuestra modesta labor investigadora en literatura siempre hemos insistido en que la caracterización o puesta en claro de la identidad de las obras ha de hacerse empírica y temporalmente, no procediendo por abstracciones; nuestra perspectiva resulta así distinta a la asumida por muy distinguidos compañeros (el prof. García Berrio, etc.), quienes tratan de identificar los universales del imaginario antropológico que se encuentran en los textos: nosotros hemos defendido y defendemos al respecto - así lo aprendimos de José Antonio Maravall y continuamos aprendiéndolo de José María Jover-, la operatividad de la Historia de las mentalidades, que se mueve entre explicaciones específicas y no genéricas, es decir, con la individualidad histórica de cada serie literaria y de cada autor o texto de esa serie. Creemos que se incurre en tautología si decimos que un escritor, que en cuanto hombre posee ciertamente unas estructuras antropológicas en su imaginario, escribe de acuerdo con tales imágenes antropológicas universales y características de la especie: lo histórico - y la literatura es una serie o historia poética- es siempre individual y específico, no universal y genérico; así la lingüística generativa pierde también contenido empírico en cuanto tal ciencia del lenguaje (no en cuanto ciencia psicológica o antropológica), si no atiende a la variedad de las lenguas y a la variación idiomática, sino nada más que a los universales linguiístico-antropológicos del hablar.

«INNOVACIÓN» Y «CAMBIO»

Sobre la diferencia entre la innovación y el cambio lingüístico escribe Coseriu:

Todo aquello en que lo hablado por el hablante -en cuanto modo lingǘístico - se aleja de los modelos existentes en la lengua por la 
que se establece el coloquio, puede llamarse innovación.[...] El cambio lingüístico («cambio en la lengua») es la difusión o generalización de una innovación (1978: 78-80).

En efecto en la lengua surge en primer lugar la innovación, es decir, un modo de hablar que varía respecto de la norma o del sistema, y el cambio idiomático propiamente dicho no sobrevendrá sino cuando esa innovación se haya generalizado y la haya hecho suya por tanto el conjunto de los hablantes. Hay innovación y luego cambio lingüístico, según veía muy bien alguna vez $\mathrm{Me}$ néndez Pidal, quien sin embargo en otras ocasiones se refería a la multisecularidad del cambio idiomático cuando en realidad lo que quería expresar era la multisecularidad en la difusión de la innovación.

La linguística de Coseriu no es positivista, y tiene presentes de esta manera las opciones que hace el hablante; de esta manera escribe también:

El oyente adopta lo que no sabe, lo que le satisface estéticamente, le conviene socialmente o le sirve funcionalmente. La «adopción» es por lo tanto un acto de cultura, de gusto y de inteligencia práctica (Ibid.: 87-88)

Trata nuestro autor de explicar los motivos y el modo por los que se llega al cambio idiomático, y percibe en efecto que ese modo es el de la adopción por sucesivos hablantes de algo que no pertenecía a su acervo lingüístico: no pertenecía debido a falta de conocimiento, y encuentra que le es útil y aprovechable por necesidad comunicativa, o por gusto estético, o por necesidad social, y lo emplea en adelante. El empleo de parte de más y más hablantes de un rasgo idiomático lo generaliza, y al fin hace que tal rasgo pase a formar parte de la norma y luego del sistema lingüístico.

Para una lingüística que no participa del tono naturalista del positivismo resulta necesario apelar a la creatividad del hablante, de todos y cada uno de los hablantes, que con esa creatividad inducida funcional, social o estéticamente van adoptando las innovaciones idiomáticas y hacen de ellas en definitiva elementos del sistema y cambian así el sistema.

En literatura - por su lado- un autor adopta los rasgos de un género literario, escribe en él y contribuye por tanto a hacer la historia del mismo, al igual que adopta unos rasgos elocutivos que le satisfacen estéticamente y contribuye a la historia que ellos vayan a alcanzar en una literatura. No ocurre exactamente lo mismo que en lingüística, pues en poética la adopción de determinados procedimientos sólo se generaliza entre el grupo de escritores que adoptan un modo de escribir: unas innovaciones no se generalizan hasta el total 
de la comunidad de los escritores, como en cambio sí se generaliza un cambio lingüístico hasta el todo del sistema o de una de sus normas.

Hay de otro lado un amplio pasaje muy lúcido en la obra que estamos comentando de Coseriu, que expone en parte:

De las inumerables innovaciones que se comprueban en el hablar, sólo algunas se adoptan y se difunden, porque sólo algunas responden a posibilidades y necesidades del sistema funcional o encuentran condiciones favorables en el estado del saber lingüístico-interindividual. [...] Siendo la lengua un saber tradicional, ella se modifica más rápidamente en épocas de debilidad general del saber, pero las modificaciones hallan sus límites en la funcionalidad del sistema. Siendo la lengua un sistema funcional, ella se modifica sobre todo en sus "puntos débiles», es decir, ahí donde el sistema mismo no corresponde eficazmente a las necesidades expresivas y comunicativas de los hablantes (Ibid.: 140-141).

Ciertamente las innovaciones las adoptan los hablantes por su eficacia comunicativa o por un gusto estético, y por ello para su pervivencia han de estar conformes con el sistema idiomático (fuera del sistema no hay sino ininteligibilidad), y han de encontrar condiciones favorables para su difusión. Hoy en día la tendencia imitativa del ser humano y la inercia o falta de esfuerzo hace que los modos elocutivos que difunden la radio y la televisión se propaguen y hasta generalicen rápidamente, si bien tienen vigencia limitada temporalmente en muchas ocasiones, aunque mientras duran su vigencia social es muy amplia.

El sistema posee un punto débil allí donde no resulta comunicativamente eficaz, y así cambia fundamentalmente en relación con tales «puntos débiles» (fonológico, o léxico, etc.), aunque en un caso afortunado puede triunfar desde luego cualquier innovación que sólo supone mayor gusto estético por parte de los hablantes. Pero de todas maneras lo interno y lo externo al sistema, lo sistemático y lo extrasistemático, se conjugan en la consecución de las innovaciones y del cambio lingüístico, de manera que la secuencia o ritmo de la evolución idiomática depende «de la coincidencia o no-coincidencia entre lo funcionalmente necesario y lo culturalmente consentido» (Coseriu, 1978: 141).

En lo literario las innovaciones triunfan merced al hallazgo o logro artístico que suponen por sí mismas y merced tanto al genio de un autor como al reconocimiento de otros autores sucesivos que continúan al primero: así y sucesivamente (según es muy conocido) se siguen y reiteran $-e$ inscriben su nombre en la serie del arte verbal cada uno a su modo específico- el autor del Lazarillo, y los autores del Guzmán y del Buscón. El cambio linguiístico se impone cuando los hablantes hacen suya una innovación hasta generalizarla en el 
todo de la comunidad hablante; un subgénero o un modo de estilo se imponen asimismo si sucesivos autores adoptan y repiten tales cuales o en variante, los rasgos de género o elocutivos de autores pioneros que han innovado y se han anticipado.

\section{BIBLIOGRAFÍA}

ABAD, FRANCISCO (1983): Caracterización de la literatura española y otros estudios, Madrid, Cátedra de Lingüística General de la UNED y Distribuciones TAPIA, 1983.

Alonso, AmADo (1938): Castellano, español, idioma nacional. Historia espiritual de tres nombres, Buenos Aires, Facultad de Filosofía y Letras.

Coseriu, Eugenio (1978): Sincronía, diacronía e historia. El problema del cambio lingüístico, 3." ed., Madrid, Gredos.

García Berrio, Antonio (1973): Significado actual del formalismo ruso, Barcelona, Planeta.

LAPESA, RAFAEl (1947): Poetas del siglo XVI, Barcelona, Rauter.

MEnÉndez Pidal, RAMón (1942): La lengua de Cristóbal Colón, 5." ed., Madrid, Espasa-Calpe.

II

A María José Vega, estudiosa de alta calidad.

\section{EXPLICACIÓN}

Desde hace ya cierto tiempo uno de nuestros cursos de doctorado en la Universidad Nacional de Educación a Distancia está dedicado a «Literatura e historia de las mentalidades»; los alumnos del mismo - a quienes deseamos recordar globalmente ahora-, han dedicado por propia iniciativa sus trabajos de curso fundamentalmente al género novelístico, y lo mismo han hecho al componer algunas Memorias de licenciatura y Tesis doctorales que hemos dirigido. Así las cosas creímos en su día que era una obligación intelectual y moral nuestra plantearnos monográficamente el estudio de la novela española sobre todo posterior a hacia 1771 , y en primer término - y para empezar por el principio-, hemos llevado a cabo bastantes lecturas de textos narrativos, aunque 
desde luego insuficientes todavía en un género que ha sido tan cultivado. El futuro resulta siempre incierto y no sabemos en qué medida esta dedicación de una parte de nuestro tiempo a la novela dará como resultado alguna investigación escrita (aunque ya y sin un propósito sistemático tenemos publicadas algunas cosas); en todo caso trazamos ahora unas notas iniciales '.

\section{EL SIGLO XVIII EN LA EDAD CONTEMPORÁNEA}

El siglo XVIII se encuentra en la encrucijada de los tiempos «modernos» con los llamados tiempos «contemporáneos», y lo mismo cabe considerarlo en diferentes aspectos en tanto perteneciente a una Edad histórica como a la otra; según su cronología respectiva unos hechos de la centuria resultarán adscribibles propiamente al Antiguo Régimen y otros a la Edad Contemporánea. Estamos ciertamente ante una centuria compleja que se halla en el camino entre dos Edades históricas, y que posee rasgos de la una y de la otra. Entre los autores que lo han advertido así se encuentra el gran maestro don Antonio Domínguez Ortiz, quien ha escrito alguna vez:

El siglo XVIII lo mismo puede considerarse como la etapa final del Antiguo Régimen que como el pórtico de la Edad Contemporánea; en realidad participa de ambos caracteres $y$, aunque con variedad de matices, presenta una básica unidad en todas las naciones del occidente europeo (1980: 313 ).

Se trata desde luego de un siglo mixto o mezclado - si cabe decirlo así-, cuya unicidad fundamental en las naciones europeas occidentales subraya Domínguez Ortiz en lo que viene a ser objetivamente una objeción a las tesis de Américo Castro: el Setecientos no se nos aparece pues en tanto una herencia petrificada del casticismo español, sino como una situación histórica homogénea con la de las naciones del entorno en el que nos insertamos en la civilización.

Esta centuria quedó ya englobada con los tiempos contemporáneos en el tomo IV/1 de la Historia social y económica de España y América de Vicens (1958) —que resultó un logrado volumen hecho por el propio Vicens, por Juan

Nuestro otro curso de doctorado se dedica actualmente a «El diccionario como género literarion, y antes del mismo y luego en conexión con él venimos haciendo a su vez un conjunto de trabajos que desearíamos no abandonar nunca: el análisis de los Diccionarios y su historia constituye un campo de investigación muy atractivo y de relieve. 
Mercader y por el mismo Antonio Domínguez Ortiz-, y en realidad para tratar de lo contemporáneo hay que retrotraerse siempre al Setecientos ${ }^{2}$.

Si nos situamos en la cuestión de los orígenes de la novela decimonónica, habremos de ir a las décadas finales del siglo XVIII: ciertamente son varias las realidades culturales e históricas del Ochocientos que se retrotraen al siglo anterior.

\section{Historia de la novela como Sociología de la NOVEla}

Según es bien sabido uno de los textos clásicos para nuestro asunto es el de don José Fernández Montesinos de Introducción a una Historia de la novela en España en el siglo XIX. Montesinos escribía en 1954 y hacía un postulado de clarividente sentido común: que trazar la Historia de la novela española moderna suponía hacerse cargo a la vez de autores y textos, y también de empresas editoriales y de lectores. La Historia literaria para ser en verdad histórica - proclamaba nuestro autor-debe hacerse una sociología literaria atenta al escritor, a los intereses de empresa y a la reacción de las masas de lectores (1983: XI).

Más en particular y aplicada a lo novelístico, la tesis de nuestro autor decía:

La historia nos dice que apenas ha habido novela digna de este nombre hasta el advenimiento de la burguesía al rango de clase directora y el despertar de lo que se ha llamado el «gran público». [...] La novela es un género destinado a un público, y cuando ese público no existe no hay novela. Entre otras cosas porque entre el creador y su público ha de existir siempre un intermediario - impresor, editor- que sólo surge cuando posibilidades de lucro lo acucian. [...] No hay novela sin editor y no hay editor sin público. Sin la consideración atenta de este triángulo: autor, editor, público, es imposible hacer una historia de la novela. $[. .$.$] Recurriendo al paralelo forzoso del teatro [...] lle-$ garíamos a las mismas conclusiones (1983: XII-XIII).

El crítico granadino postulaba una Historia de la novela española moderna que tuviese en cuenta en efecto a autores, editores y público, y en tal orientación ha llevado a cabo luego su trabajo Juan Ignacio Ferreras. Montesinos

${ }^{2}$ Distintos autores liberales han gustado de la dedicación al Setecientos: Vicens, Mercader y Domínguez Ortiz, y asimismo Marañón, Pedro Salinas, Ángel del Río, José Antonio Maravall, etc. Existe también desde luego una visión historiográfica conservadora de la centuria. 
enfocaba programáticamente un análisis de la novela y la burguesía que tuviese presente en todo caso al público total y a los editores: vastísima empresa de la que alcanzó a hacer nueve volúmenes, y a la que ha dedicado luego toda su vida investigadora el otro estudioso mencionado profesor Ferreras ${ }^{3}$.

Cuatro años más tarde de las palabras suyas citadas, Montesinos proclamó de nuevo la necesidad metodológica de ir a una sociología literaria, y subrayó asimismo la filiación orteguiana del enfoque:

Yo seguía siendo - proclama también-más ortodoxamente orteguiano. Yo no podía olvidar que en sus años de más admirable madurez, Ortega nos enseñaba que la historia de las ciencias y disciplinas del espíritu no podía ser otra cosa que alta sociología, ya que ninguna de esas actividades podía darse en el vacío. [...] El que escribe [ una comedia, una novela, un poema épico, un ensayo] se dirige a un público, y las apetencias de ese público condicionan su obra. [...] No había escape. Hacer historia literaria era hacer sociología literaria (1970: $14-15)^{4}$.

Por motivo de la guerra española y la guerra mundial don José Montesinos "casi nada pud[o] escribir entre los años 1936-1946" (lbid.: 15), pero de todas formas alcanzó a darnos — según queda dicho— nueve tomos de «Estudios sobre la novela española del siglo XIX», y luego su planteamiento ha fecundado otros posteriores.

\section{MÁS DE UN SIGLO Y MEDIO DE DECADENCIA DE LA NOVELA}

De otra parte el crítico granadino hacía ver en la Introducción a una Historia de la novela... que la gran lírica española del XVII se hallaba íntimamente adscrita al genio de la lengua y era incomunicable, y que la comedia - asimismo de tupida raigambre nacional- - se prestó menos a la exportación; el caso de la novela cervantina no era el mismo: «La novela se le escapa a España literalmente de las manos, y es más allá de sus fronteras donde empieza a mos-

${ }^{3}$ Es de lamentar - según alguna vez hemos sugerido- el olvido casi completo que de la obra crítico-literaria referida a Lope, los escritores erasmistas, diferentes aspectos de los siglos XVI y XVII, la novela modema, etc., que hizo José Fernández Montesinos, parecen tener algunos de los actuales estudiosos de la crítica literaria. Más en general es un hecho objetivo la consciente minusvaloración o desestima - no menos moral e intelectualmente lamentable- que en ocasiones se hace de todo lo que viene del «Centro de Estudios Históricos» y de Menéndez Pidal.

${ }^{4}$ Estas palabras datan de 1958. 
trar una sorprendente fecundidad» (1983: 1-2); sobre esta fecundidad abundó asimismo Dámaso Alonso, según se sabe ${ }^{5}$.

A España se le escapa la novela de las manos, y de esta manera pudo ocurrir - proseguía su relato Montesinos- «que desde mediados del siglo XVII apenas hay novela española que merezca este nombre», y que «el nombre de España no cuenta para nada en la historia de la novela durante el siglo XVIII, aunque lo mejor que la novela europea produce entonces es español de origen" (1983: 2). Para estudiar la novela española moderna habremos de ir al Setecientos, pero hacia su final: cabe saber que en efecto la novela española propiamente dieciochesca no cuenta en la novelística de la centuria; desde luego debe atenderse a qué le ocurrió al género en nuestro XVIII, y de ello se ocupó en 1987 Juan Ignacio Ferreras, en un pequeño libro que acaso fue el primero - señalaba el propio autor - dedicado enteramente a la novela de tal siglo.

HACIA $1771 / 1780$

El planteamiento de Ferreras dice que si consideramos por una parte a Torres Villarroel y al Padre Isla y por otra a Pedro Montengón y a Martínez Colomer, «los dos primeros pertenecen al XVIII que intenta prolongar un pasado, Montengón y Martínez Colomer pertenecen al XVIII que intenta renovar» (1987: 15). Los primeros son obviamente mejores escritores que los segundos, pero estos tienden ya hacia otra forma de novelística; a su vez don Diego de Torres y Villarroel cultiva la novela alegórica por ejemplo en las Visiones y visitas con Don Francisco de Quevedo (Ibid.: 43).

La producción «continuista e imitadora» de la novela del pasado empieza a quebrarse hacia el último cuarto del Setecientos: así y con El Rodrigo de Montengón «nos encontramos ya con ciertas limitaciones - recuerda Ferreras- ante la primera piedra de lo que será la novela histórica española» (1987: 50), y de ahí su relieve desde el punto de vista histórico. En esta corriente renovadora cabe encontrar los inicios de la novela del Ochocientos.

5 «En la historia de la influencia de Cervantes en el mundo - mantenía don Dámaso-, la obra de Fielding ofrece esta doble cualidad: es la huella más importante de Cervantes porque tiene una trascendencia inmensa para la historia posterior de la novela, y es al mismo tiempo la huella más evidente. [...] Francia y Alemania, las dos, recibieron desde luego su parte de quijotismo directo, pero también bebieron un largo trago de savia quijotesca a través de las obras de Fielding, del mejor de los imitadores de Cervantes. Naturalmente que lo mismo, y más aún, se puede decir de Inglaterra» (1985: 630-631). 
En todo caso y para tener idea de la novela española en el XVIII hay que atender a todo el transcurrir de la centuria (Ferreras va enumerando a novelistas como Francisco Párraga Martel, José Moraleja Navarro, Fulgencio Afán de Ribera, ..., Torres, Isla), si bien lo que se podemos considerar novela española moderna arranca acaso desde Cadalso o desde los años ochenta en adelante.

Con posterioridad a Juan Ignacio Ferreras otro investigador del XVIII, Joaquín Álvarez Barrientos, ha abordado con gran aliento de nuevo la historia de la novela de nuestro Setecientos, y ambos autores no coinciden completamente en la percepción que tienen de los hechos (Álvarez Barrientos: 1991); este segundo crítico no obstante también engloba en tanto un todo unitario la novela desde «los años ochenta a la Guerra de la Independencia», y comprueba que en verdad en las décadas anteriores a 1808 la novela experimenta un gran desarrollo posibilitado por la existencia de un público considerable.

Joaquín Álvarez coincide con Ferreras en que la Vida de Torres Villarroel no es una novela (1991: 79), pero por otro lado matiza:

a) En Fray Gerundio se recupera el espíritu cervantino y así se dan «elementos de la novela moderna».

b) De todas formas lo moderno en los lustros finales del siglo es escribir de acuerdo con lo sentimental.

c) En el caso de Pedro Montengón no puede hablarse propiamente de renovación de la novela en cuanto técnica novelística (Ibid.: 85, 92, 225, 236).

Creemos que las percepciones de ambos estudiosos —-Juan Ignacio Ferreras y Joaquín Álvarez Barrientos- no resultan absolutamente incompatibles, y que los enunciados suyos que hemos recogido pueden compatibilizarse porque atienden a aspectos distintos que presentan los textos.

Diremos en fin que el estudioso que quiera hacerse cargo en conjunto de los problemas deberá tener en cuenta el total de la centuria, si bien ha de advertir la ruptura hacia el futuro que se inicia acso en los finales de la misma, en los años setenta u ochenta, si no antes ${ }^{6}$. En realidad ocurren por entonces otras innovaciones, además de la que se produce en la novelística: asistimos a la plena Ilustración, al nacimiento de la "Gramática» de la Real Academia Española y de su Diccionario en un tomo -el Diccionario común o usual que llega hasta nuestros días-, al pensamiento ideológico liberal dentro de nuestra

' La relación interior que mantienen entre sí algunos de los hechos políticos a lo largo de la secuencia del siglo está tratada por ejemplo en los capítulos «España y la Paz de Utrech» y «La Diplomacia de la llustración» del libro de JOSÉ MARta JOVER España en la política internacional... (pp. 13-110). 
Ilustración, etc. Si el mundo contemporáneo surge hacia 1770, varios rasgos de contemporaneidad y por tanto de actualidad vigente surgen asimismo por entonces entre nosotros.

En otra monografía el mismo J. I. Ferreras ha abordado la secuencia que experimenta la novelística en las décadas primeras del Ochocientos, y ha notado la extensión que alcanza el cultivo del género, lo que posibilita la existencia de una serie que — según ocurre siempre en literatura- precipitará en un momento determinado en sus mejores logros ${ }^{7}$; en definitiva ocurre que avanzada ya la segunda mitad del Setecientos y desde luego «durante las tres primeras décadas del siglo XIX» nace «la novela moderna» española, la cual «continúa informando en buena parte el novelar actual español» (Ferreras, 1973: 311).

\section{«CORnelia Bororquia»}

Uno de los muchos textos que surgen en estos orígenes de la novela decimonónica es la narración Cornelia Bororquia, según Gérard Dufour aparecida por vez primera en París en 1801, y en segunda edición «revista, corregida y aumentada» en 1802 (Dufour, 1987: 53); su autor fue Luis Gutiérrez.

La obra - glosa bien su editor Dufour - constituye una «defensa e ilustración de la tolerancia religiosa» y por tanto una condena de la Inquisición (Ibid.: 41-42); en general una condena del absolutismo. Vemos así por ejemplo al noble Meneses escribirle al Gobernador de Valencia:

Un hombre sabio y razonable conoce la crueldad e injusticia de la Inquisición y jamás aprueba sus atropellamientos y vejaciones, antes bien los vitupera en secreto. Un reo del santo, o por mejor decir, del infernal oficio, es siempre a los ojos de las personas sensatas una desventurada víctima sacrificada o al furor, o al interés, o a la ambición de

7 He aquí el párrafo de contenido metodológico en que nuestro autor expone esto, y con cuyo espíritu nos identificamos: «En la España del primer tercio de siglo se cultiva sin mucha fortuna la novela, pero se cultiva, y con mayor extensión y hasta profundidad de lo que se ha venido creyendo hasta ahora. Lo importante en el devenir literario de un género no es solamente la aparición de una obra genial, sino el nacimiento y desarrollo de una tendencia que ha de permitir en su día la aparición de la obra que hemos llamado genial. Claro que toda Historia de la literatura ha de basarse en las obras geniales, puesto que éstas justifican finalmente incluso la existencia de esa Historia de la literatura, pero si entendemos por Historia algo más que un catálogo de nombres ilustres, si entendemos por Historia la descripción de las conciencias colectivas o de grupo que produjeron y que se materializaron a un nivel artístico que llamamos novela, el novelar de la época que estudiamos no es pobre ni mucho menos" (FerRERAs, 1973: 129-130). 
unos hombres que son el azote de la humanidad y la deshonra de la religión (Dufour, 1987: 89).

No cabe pues pensar en infamia propia ante el parecer de las personas sensatas, cuando se es víctima de esta intolerancia absoluta y ciega de la Inquisición, que no se reduce en definitiva sino a unos hombres que deshonran la religión por sus ambiciones e intereses.

En una de las cartas que componen la obra es Bartolomé Vargas quien se dirige a su propio hermano el inquisidor Cipriano Vargas, y le señala «el capricho y la mentira" del proceder inquisitorial, proceder que se diría hace posible todo lo que ideológicamente ha determinado que es necesario. Luis Gutiérrez pone en efecto en la pluma de Bartolomé Vargas:

Yo más quisiera tener un hermano verdugo o carnicero, que no inquisidor. Un tribunal bárbaro que no tiene otro código sino el capricho y la mentira, exige por jueces unos hombres sin honor, sin conciencia y sin sentimientos. Digo el capricho y la mentira porque todo lo que repugna a la idea y al sentimiento de un Dios propicio y benéfico se opone diametralmente a nuestra santa religión, y por consecuencia es obra vuestra. Así es que vuestra corta vida es un largo tejido de horrores y atrocidades. Tan pronto mandáis quemar un centenar de judíos, tan presto encendéis vuestras hogueras para una muchedumbre de herejes $[\ldots]$. La razón clama incesantemente contra semejantes injusticias, la religión condena unas acciones tan enormes y crueles, y el brazo levantado del supremo juez se descargará contra sus indignos y sanguinarios ministros (Ibid.: 92-93).

El trazado que hace el autor del espíritu inquisitorial, de lo inquisitorial, es impecable: los jueces del llamado Santo Oficio carecen en efecto de conciencia, de sentimientos y de honor, y han hecho suya la indistinción del mal, es decir, que incurren en la banalidad de no saber percibir el mal que causan a sus víctimas: proceden de esta manera según el capricho y —cuando les hace falta- según la mentira.

La religión nos presenta a un Dios benéfico y siempre propicio, y son sus ministros quienes sin embargo incurren en una larga serie - tan larga como sea su vida- de horrores: la razón y la propia religión claman en contra de estos ministros sagrados, y será el Juez supremo quien descargue su fuerza contra ellos.

Bartolomé Vargas escribe asimismo a Meneses en la novela, y creemos percibir en lo que refiere en uno de sus párrafos en que hace una diatriba anticlerical, la expresión del valor de la sociabilidad y del gusto natural por el vivir que es sin duda una concepción de la llustración: 
Estos malditos frailes son los que han pervertido a los hombres. Enemigos del género humano, enemigos unos de otros, incapaces de conocer las dulces ventajas de la sociedad, ellos son, ellos son los que han propagado la superstición y el fanatismo. ¿Qué podíamos esperar de unos hombres duros [...] que creen irritar a Dios si disfrutan de sus beneficios; que imaginan agradar al autor detestando sus obras; que pasan su vida llorando, gimiendo, cantando, orando, aborreciéndose a sí mismos y destruyendo lentamente la existencia que la naturaleza misma les ordena conservar? Infelices en sus sagrados cubiletes, no piensan sino en hacer desventurados a los demás hombres. [...] ¿Cómo es que contamos con unas gentes que santifican la perfidia, y que reducen toda especie de moralidad a un sistema que aun cuando no fuera falso, absurdo y pernicioso, se halla en contradicción con las pasiones, con los intereses y con el corriente de la vida humana? (Ibid.: 105).

Los intereses de la vida y las dulces ventajas de la sociedad quedan proclamados en tanto valores en contra de los que los frailes viven y quieren hacer vivir a los demâs; estos valores parecen típicos de una mentalidad ilustrada que es la que ahora nos muestra Luis Gutiérrez. Un estudioso como José Antonio Maravall ha advertido que en efecto el Setecientos supera la baja cota del aislamiento individual que definía a la cultura del Barroco, y concluye un razonamiento al respecto con estas palabras: «La sociedad: toda la obra de los ilustrados fue un denodado esfuerzo por descubrir esa extensa plataforma de la convivencia humana» (Maravall, 1991: 256 y 265).

Particularmente severa resulta la Carta XV de Cornelia Bororquia, en la que de nuevo Bartolomé Vargas impreca a su hermano Cipriano el inquisidor:

Para penetrar las imaginaciones y conducirlas por medio del terror, representasteis a Dios como un tirano, le adornasteis con todas vuestras horribles pasiones, con la cólera, el odio, la venganza, la parcialidad, la inconstancia, los celos: hicisteis de él un ser cruel, [...] en una palabra, hicisteis un Dios imaginario, pero semejante a los tiranos de la tierra, y de este modo divinizasteis por decirlo así los vicios de estos últimos, y acostumbrasteis a los hombres a sufrir con paciencia sus injusticias, sus vejaciones, sus latrocinios. Después de haber dado a los hombres esta idea de la Divinidad, no os fue difícil persuadirlos que sus jefes eran sus representantes en este mundo, que su autoridad venía del Cielo, y que era ofender a Dios el resistir y desobedecer a los tiranos. De este modo habiendo sido el apoyo del despotismo, obtuvisteis por reconocimiento el privilegio de engañar libremente al pueblo y de enriqueceros a costa de su ignorancia [...]. Tal fue el pacto entre el trono y el sacerdocio: engañar y amedrentar para dominar y robar. (Ibid.: 114). 
Estos párrafos se hallan inspirados en d'Holbach, según nos muestra el editor de nuestro texto, y proclaman cómo en efecto la idea de la Iglesia establecida ha sido a veces la de equiparar por una parte los poderes terrenales con la autoridad divina, y por otro lado la de que resistir a esos poderes terrenales era ofender a Dios.

En fin el personaje Meneses exclama: « Oh religión, religión! [...] También con tu velo se cubre la maldad, [...] y tú sirves de sagrado pretexto para justificar las pasiones más horribles y vergonzosas" (Ibid.: 177); estamos ante una insistencia en lo mismo, en que las deformación intelectual y las pasiones humanas están en la Iglesia establecida por detrás de la actuación religiosa, que no se torna sino en un pretexto para dar salida a tales pasiones. Meneses se pregunta al fin que cuándo será el día en que los príncipes se desengañen de la maldad de los pérfidos inquisidores, y entonces, «atentos a sus intereses y a los de sus pueblos, mand[e]n poner fuego a los tremendos edificios donde se albergan majestuosamente estos perversos, escándalo de la humanidad y deshonor de la razón y de la justicia»; la respuesta es la de que tal dichosa época «está muy remota y lejana» (Ibid.: 177-178).

El personaje Meneses apela al escándalo de la humanidad y el deshonor de la razón, lo que constituye asimismo una apuesta ilustrada: la humanidad y la razón se encuentran ultrajadas por el llamado Santo Oficio, y a favor de ellas ha de desearse otra época en la que ya no imperen los poderes absolutos.

La crítica estima que ciertamente en Cornelia Bororquia se dan unos personajes que viven y saben moverse y expresarse en el universo novelesco, y con tal apreciación coincidimos nosotros.

\section{BIBLIOGRAFIA}

Alonso, Dámaso (1985): Obras Completas. VIII. Comentarios de texto ( «ervantes en Fielding»), Madrid, Gredos.

Álvarez Barrientos, JoAQuín (1991): La novela del siglo XVIII, Madrid y Gijón, Júcar.

Dominguez OrTiZ, ANtonio (1980): Hechos y figuras del siglo XVIIl español, segunda ed. ampliada, Madrid, Siglo Veintiuno.

Dufour, GÉrARD, ed. (1987): Cornelia Bororquia o la víctima de la Inquisición, Alicante, Diputación Provincial.

F. Montesinos, José (1983): Introducción a una Historia de la novela en España en el siglo XIX, cuarta ed., Madrid, Castalia.

F. MONTESINOS, JosÉ (1970): Ensayos y estudios de literatura española, Madrid, Ed. Revista de Occidente. 
Ferreras, JuAn Ignacio (1973): Los orígenes de la novela decimonónica (18001830), Madrid, Taurus.

Ferreras, Juan Ignacio (1987): La novela en el siglo XVIII, Madrid, Taurus.

JOVER, JoSÉ MARÍA (1999): España en la política internacional. Siglos XVIII-XX, Madrid, Marcial Pons.

Maravall, José Antonio (1991): Estudios de Historia del pensamiento español. Siglo XVIII, Madrid, Mondadori. 